\title{
Development of internal fine structure in stretched rubber vulcanizates
}

\section{$\operatorname{AUTHOR}(S)$ :}

Tosaka, Masatoshi; Toki, Shigeyuki; Che, Justin; Rong, Lixia; Hsiao, Benjamin S.

\section{CITATION:}

Tosaka, Masatoshi ...[et al]. Development of internal fine structure in stretched rubber vulcanizates. Journal of Polymer Science Part B: Polymer Physics 2011, 49(16): 1157-1162

\section{ISSUE DATE:}

\section{1-06-08}

URL:

http://hdl.handle.net/2433/197326

\section{RIGHT:}

This is the peer reviewed version of the following article: Tosaka, M., Toki, S., Che, J., Rong, L. and Hsiao, B. S. (2011), Development of internal fine structure in stretched rubber vulcanizates. J. Polym. Sci. B Polym. Phys., 49: 1157-1162, which has been published in final form at http://dx.doi.org/10.1002/polb.22290; This is not the published version. Please cite only the published version.; この論文は出版社版でありません。引用の際には出版社版をご確認ご利用くだ 


\section{Development of Internal Fine Structure in Stretched Rubber Vulcanizates}

Masatoshi Tosaka $^{1 \dagger}$, Shigeyuki Toki ${ }^{2}$, Justin Che ${ }^{2}$, Lixia Rong ${ }^{2}$ and Benjamin S. Hsiao ${ }^{2}$

${ }^{1}$ Institute for Chemical Research, Kyoto University, Gokasho, Uji, Kyoto 611-0011, Japan

${ }^{2}$ Department of Chemistry, State University of New York at Stony Brook, NY 11794-3400, USA.

${ }^{\dagger}$ Corresponding author

Tel: +81-774-38-3062, Fax: +81-774-38-3069, E-mail: tosaka@scl.kyoto-u.ac.jp

\section{Abstract:}

Small-angle X-ray scattering (SAXS) pattern and tensile stress during relaxation of stretched rubber vulcanizates (synthetic polyisoprene) were measured simultaneously at room temperature and at $0{ }^{\circ} \mathrm{C}$. The samples were quickly stretched to the prefixed strain and then allowed to relax for $1 \mathrm{~h}$. In every SAXS pattern, the intensity distribution was elongated along the equator, indicating the formation of structures elongated in the stretching direction. The so called "two-spots pattern" corresponding to the long period of stacked lamellar crystals did not appear even when the critical strain to induce crystallization was exceeded. On the other hand, even below the critical strain, additional development of equatorial streaks was detected in the differential SAXS patterns. This result suggests the growth of the density fluctuation elongated in the stretching direction, which is not directly related to strain-induced crystallization.

\section{KEYWORDS}

natural rubber, strain-induced crystallization, network polymer, 


\section{MAIN TEXT}

Plant-derived natural rubber (NR) is a unique and indispensable material for modern civilization because it exhibits both the high extensibility (softness) and toughness (tensile strength and crack-growth resistance). Though it has been desired to understand the origin of the strength of vulcanized NR, there have been little studies by small-angle X-ray scattering (SAXS) to analyze the internal fine structure that should be responsible for the mechanical properties. In this article, we report on finding the "growth" of elongated structures aligned in the stretching direction, even below the critical strain of crystallization.

It is widely accepted that the strength of vulcanized NR largely depends on the ability to crystallize upon high extension. Accordingly, the internal fine structure of stretched NR samples has been studied in terms of strain-induced crystallization, mainly by wide-angle X-ray diffraction (WAXD). On the basis of the WAXD experiments, the authors have already reported that crystallization of stretched NR starts above a critical strain despite the difference in network-chain density. ${ }^{1,2}$ Morphological features of strain-induced crystallites such as crystallite size and orientational fluctuation have also been clarified. ${ }^{2}$ For a detailed discussion on the reinforcing mechanism by strain-induced crystallization, in addition to the above information, arrangement of the crystallites must be examined. For the latter study, SAXS is more suitable than WAXD.

However, it has been difficult to obtain meaningful data for this system by SAXS because practical samples of NR vulcanizates contain considerable non-rubber components that mask the signal from the internal fine structure of the rubber component. For example, $\mathrm{ZnO}$ has a higher scattering power to $\mathrm{X}$-ray than rubber molecules, though it is necessary in order to prepare practical vulcanized NR products. Proteins and lipids are also highly-scattering objects in the rubber matrix. Despite the efforts in the previous works to reduce the effects of the non-rubber components in the scattering patterns, ${ }^{3-5}$ the authors could find only two reports ${ }^{6,7}$ on the SAXS studies of stretched NR vulcanizates to identify the internal fine structure. Even in the latter SAXS studies, the specimens were cooled down to low temperature (below $-10^{\circ} \mathrm{C}$ ) in order to examine the morphology of thermally-induced crystals, and the so-called "two-spots pattern" that is typical for the stacked-lamellar structure was analyzed. SAXS analysis around room temperature may not have been fully performed so far, though it is important for the study in the practical service condition.

In this study, the development of internal fine structure in the stretched rubber samples in relation to the tensile stress was examined by SAXS and simultaneous tensile 
measurements. Our strategy was to expand the sample quickly to a predetermined strain ratio $\left(\alpha_{s}\right)$ and examine the "changes" in the SAXS patterns to elucidate the structure formation during the relaxation process at the constant strain; the origin of the elapsed time $(t=0)$ was defined as the moment when the deformation was stopped. In order to rule out the structure formation of naturally occurring non-rubber components (namely, proteins and lipids), synthetic isoprene rubber (IR) was used instead of NR. Furthermore, the scattering from the other non-rubber components was subtracted by calculating the differential of the SAXS patterns during the relaxation process at the constant strain.

Three types of IR vulcanizates (IR1T, IR3T and IR5T) with different network-chain densities $\left(2.31 \times 10^{-4}, 1.76 \times 10^{-4}\right.$ and $1.49 \times 10^{-4} \mathrm{~mol} / \mathrm{cm}^{3}$, respectively) were examined. Figures $1 \mathrm{a}$ and $1 \mathrm{~b}$ show the SAXS patterns of IR3T just after the completion of deformation at $0{ }^{\circ} \mathrm{C}$. (In order to highlight the weak signals, the logarithmic brightness-scale is applied in this article.) These patterns are presented as typical examples of as-recorded (unprocessed) ones. It is clearly recognized that the scattering spreads along the equator, indicating the existence of density fluctuation elongated in the stretching direction. The degree of intensity localized on the equator increased with increasing the strain ratio, $\alpha_{\mathrm{s}}$. It was unexpected to find that the network-chain density did not affect the degree of intensity localization that much. The SAXS patterns of the other samples (IR1T and IR5T) are, therefore, not shown here. Meanwhile, the two-spots pattern related to the stacked-lamellar crystals was not observed, even when the $\alpha_{\mathrm{s}}$ values exceed the critical strain to induce crystallization. ${ }^{1}$ Note that the scattering pattern in this figure includes information not only of the internal fine structure of the rubber component but also the dispersion of the non-rubber components. Accordingly, the as-recorded SAXS patterns were not directly analyzed by conventional methods.

The development of internal fine structure during the relaxation process was of our interest. In the time series of as-recorded two-dimensional (2D) SAXS patterns, however, we could not find discernible changes. This situation is exemplified in Figure 1c, in which the intensity distributions around the equator of the SAXS patterns at $t=0 \mathrm{~s}$ (initial) and at $t=$ $3900 \mathrm{~s}$ are compared for the case corresponding to Figure 1b; the two plots are almost overlapping.

Even if there were some changes in the internal fine structure, the degree of such changes might be too small compared to the stationary scattering components which have been formed during the deformation process. In order to find the slight changes that could 
have been buried in the stationary components, the difference between the SAXS pattern after a certain elapsed time and the initial one (at $t=0 \mathrm{~s}$ ) was calculated. By this processing method, both the scattering components of the pre-existed internal fine structures and the dispersion of the non-rubber components were subtracted. Note that the sample was neither deformed nor moved during the SAXS measurement. Accordingly, the differential SAXS patterns should purely reflect the slight structural changes during the relaxation process. Figure 2 shows the examples of the differential SAXS patterns. The development of the streaks on the equator is clearly recognized, while the two-spots pattern is still not observed. The intensity of the equatorial streak in the differential was on the order of only a few percent of the original SAXS pattern but was above the level of signal-to-noise ratio. The similar development of the equatorial streaks in the differential SAXS patterns was found in all of our experiments, i.e., $3.5 \leq \alpha_{\mathrm{s}} \leq 5$ at room temperature and $2.5 \leq \alpha_{\mathrm{s}} \leq 6$ at $0{ }^{\circ} \mathrm{C}$.

Figure 3 shows the integrated intensity of the differential SAXS patterns (e.g., Figure 2 ), $I_{\text {def, }}$ as a function of elapsed time, $t$. It appears that, at first, $I_{\text {def }}$ slightly increases almost linearly with the logarithm of elapsed time, and after certain induction period of ca. $t=1000 \mathrm{~s}$, the increase of $I_{\text {def }}$ is accelerated. We suspect, however, that such inflections in Figure 3 are not real features but artifacts due to the limitation of the observing $q$ range, since the streaks are gradually protruding from the beam stop (see Figure 2). It is more likely to interpret that the characteristic size of the growing structure was, at first, so large that the corresponding change of the scattering has been almost hidden inside the beam stop. With elapsed time, the spatial frequency of the growing structure may extend over the higher side (namely to the smaller structure). Though the overall evolution of the structure may have been almost proportional to the logarithm of elapsed time, the early stage may not have been detected in the current experimental condition. Only after the smaller structures were sufficiently developed, the scattering may have protruded from the beam stop.

The stress relaxation behavior with elapsed time was also examined. Because the absolute values of tensile stress are largely different according to both the network-chain density and the $\alpha_{\mathrm{s}}$ value, the progress of stress relaxation was compared on the basis of normalized stress, $\sigma_{\mathrm{n}}(\mathrm{t})$; $^{8-10}$

$$
\sigma_{\mathrm{n}}(\mathrm{t})=\sigma(t) / \sigma(0)
$$

where $\sigma(t)$ is the stress value at elapsed time $t$ and $\sigma(0)$ is the stress at the moment when the deformation is stopped. Figure 4 shows the stress relaxation behavior of IR3T which was 
measured simultaneously with the SAXS patterns. Other samples showed almost the identical behavior; we have already reported that the stress relaxation behavior in this type of plot is almost independent of network-chain density for this series of samples. ${ }^{8-10}$ While there were inflections in the plot of $I_{\text {def }}$ (Figure 3), no such inflections were observed in the plot of $\sigma_{\mathrm{n}}(\mathrm{t})$ (Figure 4). This is another reason that we suspect the inflections in Figure 3 to be artifacts.

It is seen that the stress relaxation is accelerated with increasing $\alpha_{s}$. According to previous studies, this trend can be explained as a result of strain-induced crystallization. ${ }^{8-16}$ The critical strain to induce crystallization of IR is ca. 4.5 at room temperature, and the critical value decreases with decreasing specimen temperature. ${ }^{1}$ Correspondingly, below the critical strain, the stress relaxation behavior is almost identical $\left(\alpha_{s}=3.5\right.$ and 4 at room temperature). In other words, crystallization progressed depending on the degree of stress relaxation. We therefore expected more increase in $I_{\text {def }}$ for the larger $\alpha_{s}$. However, it was contrary to our expectation to find that, in some cases, $I_{\text {def }}$ increased more rapidly as $\alpha_{\mathrm{s}}$ decreases, and even below the critical strain of crystallization, the streaks have obviously grown in the differential SAXS patterns. That is to say, the growth of the fine structure in question is not directly related to strain-induced crystallization. It is also not likely to attribute this observation to plastic deformation of molecular chains or scission of weak cross-linking (namely, polysulfidic bonds), considering the less occurrence of stress relaxation for the lower $\alpha_{s}$ condition. Formation of the internal structures elongated in the stretching direction has been observed by transmission electron microscopy and atomic force microscopy. ${ }^{17-20}$ However, the growth of the internal structures has not been expected to occur in this way. Currently, we are not sure how this phenomenon can be understood, though the following additional features were read out from Figure 3. At $0{ }^{\circ} \mathrm{C}$ (Figures 3a, 3b and 3c), the increase of $I_{\text {def }}$ was faster for the sample with the higher network-chain density, i.e., of smaller network-chain length. This may be due to the smaller characteristic size of the growing structure, leading to the faster protrusion from the beam stop. Accordingly, the size of the network is thought to affect the characteristic size of the growing structure. At room temperature, however, the trend seems to be inversed (compare square symbols in Figure 3d) while the increase of $I_{\text {def }}$ is largely accelerated. (Note that the scale of the ordinate of Figure $3 \mathrm{~d}$ is different from the others.) Such a result could be derived if the chain mobility increased with temperature and the degree of acceleration of the structure formation is larger for the sample with the lower network-chain density. A possible explanation for this phenomenon 
considering these trends could be segregation of molecular chains to unoriented and oriented domains. Because the cross-linking density is fluctuated in the specimen, degree of stretching of molecular chains should be different from place to place; most of the network chains are considerably relaxed even in the highly stretched rubber samples. ${ }^{21,22}$

In conclusion, we detected the growth of the density fluctuation that is elongated in the stretching direction. While the two-spots pattern that is attributable to the stacked-lamellar structure was not detected even in the crystallized samples, the development of equatorial streaks in the differential SAXS patterns was clearly recognized even below the critical strain to induce crystallization. The differential SAXS patterns suggested the growth of the density fluctuation elongated in the stretching direction, and we found that the growth of the fine structure in question is not directly related to strain-induced crystallization. The detailed mechanism of the growth of the density fluctuation is the subject of our future work.

\section{EXPERIMENTAL}

\section{Materials}

Sheets ( $1 \mathrm{~mm}$ thick) of vulcanized IR samples were kindly supplied by Toyo Tire and Rubber Co., Ltd. IR2200 from JSR $\left(\mathrm{M}_{\mathrm{n}}=6.58 \times 10^{5}, \mathrm{M}_{\mathrm{w}} / \mathrm{M}_{\mathrm{n}}=4.02\right)$ was used as IR. The samples with different network chain densities were prepared by changing the amount of the accelerator and sulfur, which is almost the same way as in our previous works. ${ }^{1,2,8,9,23}$ The samples were composed of 100 parts of IR, 2 parts of stearic acid, 1 part of ZnO and the following amount of $\mathrm{N}$-cyclohexyl-2-benzothiazole sulfonamide (CBS) and sulfur; for IR1T, IR3T and IR5T, CBS / sulfur (parts) were 3.0 / 4.5, 1.5 / 2.3, and 0.75 / 1.125, respectively. After mixing, these ingredients were cured at $140{ }^{\circ} \mathrm{C}$. The curing time was $25 \mathrm{~min}, 35 \mathrm{~min}$ and 50 min for IR1T, IR3T and IR5T, respectively.

Network-chain densities were estimated from the tensile properties on the basis of the rubber elasticity theory. ${ }^{24}$ Ring-shaped specimens with circumference of $50 \mathrm{~mm}$ were cut out from the sheets. Tensile measurements of these specimens were performed with a conventional tensile tester at room temperature and at $50^{\circ} \mathrm{C}$. The deformation rate was $25 \mathrm{~mm}$ / min. Network chain density $(v)$ values of the samples were estimated according to equation $(2),{ }^{24}$

$$
\sigma=v k T\left(\alpha-\alpha^{-2}\right)
$$

where $\sigma$ is the force per unit area, $v$ is the number of network-chains in unit volume, $k$ is the Boltzmann constant, $T$ is the absolute temperature and $\alpha$ is the strain ratio ( $\alpha=l / l_{0}$, where $l_{0}$ 
is the initial length of the specimen and $l$ is that of the elongated). The average values of $v$ at room temperature and at $50^{\circ} \mathrm{C}$ were estimated.

\section{SAXS measurements}

The specimens were cut out from the sheets into a dumbbell shape for simultaneous synchrotron X-ray and tensile measurements. The initial width and thickness of the parallel part of the specimen that was exposed to the X-ray were $4 \mathrm{~mm}$ and $1 \mathrm{~mm}$, respectively. This width was large enough to avoid the total reflection of the incident X-ray beam at the edge of the specimen.

The synchrotron X-ray measurements were carried out at the X27C beam-line in the National Synchrotron Light Source, Brookhaven National Laboratory, USA. The wavelength was $0.1371 \mathrm{~nm}$, the spot size was $0.39 \mathrm{~mm}$ and the camera length was $1789 \mathrm{~mm}$. The 2D SAXS patterns were recorded using a MAR CCD X-ray detector. The diffraction angle was calibrated by an AgBe standard.

A modified tensile instrument allowing the symmetric deformation of the sample was used, ${ }^{15,22,25-30}$ which permitted the focused X-ray to illuminate the same sample position during extension. The initial sample length between the clamps was $30 \mathrm{~mm}$. The strain ratio, $\alpha$, was calculated on the basis of the displacement of the clamps. The experiments were carried out at room temperature and at $0{ }^{\circ} \mathrm{C}$ in an environmental chamber. The specimen was deformed to a prefixed strain ratio, $\alpha_{\mathrm{s}}$, at $100 \mathrm{~mm} / \mathrm{min}\left(0.056 \mathrm{~s}^{-1}\right)$. The deformation was then stopped and the specimen was allowed to relax at the constant strain ratio for $1 \mathrm{~h}$ or more. ${ }^{8,9,23}$ During the deformation and relaxation processes, the SAXS patterns were recorded every $20 \mathrm{~s}$, with exposure time of $14.7 \mathrm{~s}$ or $12.7 \mathrm{~s}$. At the same time, tensile stress was recorded every $1 \mathrm{~s}$.

The images were processed using software named "POLAR" (Stonybrook Technology and Applied Research, Inc.). After subtracting the dark current, the intensity of each image was normalized according to the incident beam intensity. By assuming the scattering by air is unchanged during the relaxation process, the differential SAXS patterns were calculated. Then the summation of intensity of each pixel in the differential SAXS pattern was calculated. Finally, the summation was corrected for the thickness of the deformed specimen to obtain the final value of $I_{\text {def }}$.

\section{ACKNOWLEDGMENT}

The authors are grateful to Dr. M. Kojima of Toyo Tire and Rubber Co., Ltd. for sample preparation. This study was partly supported by a Grant-in Aid for Scientific Research 
(C), No. 20550187 from Japan Society for the Promotion of Science (to M. Tosaka).

\section{REFERENCES}

1. Tosaka, M; Kohjiya, S; Murakami, S; Poompradub, S; Ikeda, Y; Toki, S; Sics, I; Hsiao, B S. Rubber Chem. Technol. 2004, 77, 711-723.

2. Tosaka, M; Murakami, S; Poompradub, S; Kohjiya, S; Ikeda, Y; Toki, S; Sics, I; Hsiao, B S. Macromolecules 2004, 37, 3299-3309.

3. Morfin, I; Ehrburger-Dolle, F; Grillo, I; Livetc, F; Bley, F J. Synchrotron Rad. 2006, 13, 445-452.

4. Salgueiro, W.; Somoza, A.; Torriani, I. L.; Marzocca, A. J. J. Polym. Sci., Part B, Polym. Phys. 2007, 45, 2966-2971.

5. Salgueiro, W.; Somoza, A.; Marzocca A. J.; Torriani, I.; Mansilla M. A. J. Polym. Sci., Part B, Polym. Phys. 2009, 47, 2320-2327.

6. Luch, D.; Yeh, G. S. Y. J. Macromol. Sci., -Phys. 1973, B7, 121-155.

7. Schultz, J. M. In Polymer Research at Synchrotron Radiation Sources (BNL 51847); Russel, T P.; Goland, A N., Eds.; Brookhaven National Laboratory Associated Universities, Inc.: New York, 1985; pp 85-93.

8. Tosaka, M; Kawakami, D; Senoo, K; Kohjiya, S; Ikeda, Y; Toki, S; Hsiao, B S. Macromolecules 2006, 39, 5100-5105.

9. Tosaka, M; Senoo, K; Kohjiya, S; Ikeda, Y J. Appl. Phys. 2007, 101, 84909.

10. Tosaka, M Macromolecules 2009, 42, 6166-6174.

11. Miyamoto, Y; Yamao, H; Sekimoto, K Macromolecules 2003, 36, 6462-6471.

12. Kim, H-G; Mandelkern, L. J. Polym. Sci., Part A-2 1968, 6, 181-196.

13. Gent, A. N.; Zhang, L.-Q. J. Polym. Sci., Part 2001, B: Polym. Phys. 39, 811-817.

14. Gent, A. N. Trans Faraday Soc. 1954, 50, 521-533.

15. Toki, S; Sics, I; Hsiao, B S.; Tosaka, M; Poompradub, S; Ikeda, Y; Kohjiya, S Macromolecules 2005, 38, 7064-7073.

16. Gent, A. N.; Kawahara, S.; Zhao, J. Rubber Chem. Technol. 1998, 71, 668-678.

17. Göritz, D.; Sommer, J.-U.; Duschl, E. J. Kautsch. Gummi Kunstst. 1994, 47, 170-174.

18. Walters, M.H. J. Polym. Sci., Part A 1963, 1, 3091-3103.

19. Reichert, W F; Göritz, D; Duschl, E J Polymer 1993, 34, 1216-1221.

20. Watabe, H; Komura, M; Nakajima, K; Nishi, T Jpn. J. Appl. Phys. 2005, 44, 5393-5396.

21. Murakami, S; Senoo, K; Toki, S; Kohjiya, S Polymer 2002, 43, 2117-2120.

22. Toki, S; Sics, I; Ran, S; Liu, L; Hsiao, B S.; Murakami, S; Senoo, K; Kohjiya, S Macromolecules 2002, 35, 6578-6584.

23. Tosaka, M; Kohjiya, S; Ikeda, Y; Toki, S; Hsiao, B S. Polym. J. 2010, 42, 474-481.

24. Treloar, L. R. G. In The Physics of Rubber Elasticity, Third Edition; Clarendon Press: 
Oxford, 1975.

25. Toki, S; Sics, I; Ran, S; Liu, L; Hsiao, B S. Polymer 2003, 44, 6003-6011.

26. Toki, S; Hsiao, B S. Macromolecules 2003, 36, 5915-5917.

27. Toki, S; Sics, I; Ran, S; Liu, L; Hsiao, B S.; Murakami, S; Tosaka, M; Kohjiya, S; Poompradub, S; Ikeda, Y; Tsou, A H. Rubber Chem. Technol. 2004, 77, 317-335.

28. Toki, S; Sics, I; Hsiao, B S.; Murakami, S; Tosaka, M; Poompradub, S; Kohjiya, S; Ikeda, Y J. Polym. Sci., Part 2004, B: Polym. Phys. 42, 956-964.

29. Toki, S; Hsiao, B S.; Kohjiya, S; Tosaka, M; Tsou, A H.; Datta, S Rubber Chem. Technol. 2006, 79, 460-488.

30. Toki S; S. Hsiao, B; Amnuaypornsri, S; Sakdapipanich, J Polymer 2009, 50, 2142-2148. 


\section{FIGURE CAPTIONS}

Fig. 1. SAXS patterns of IR3T at $0{ }^{\circ} \mathrm{C}$. For (a) $\alpha_{\mathrm{s}}=2.5, t=0 \mathrm{~s}$ and (b) $\alpha_{\mathrm{s}}=6, t=0 \mathrm{~s}$, the stretching direction of the specimen is vertical and the bar corresponds to $q=0.1 \mathrm{~nm}^{-1}$. (c) shows the intensity distribution near the equator of the SAXS patterns of IR3T, $\alpha_{\mathrm{s}}=6, t=0 \mathrm{~s}$ and $3900 \mathrm{~s}$. The range of integration is $\pm 30^{\circ}$ from the equator.

Fig. 2. Differential SAXS patterns. (a)-(c): IR1T, $\alpha=2.5$ at $0{ }^{\circ} \mathrm{C}$. (d)-(f): IR3T, $\alpha=6$ at $0{ }^{\circ} \mathrm{C}$. (g)-(i): IR5T, $\alpha=3.5$, at room temperature. The scale bar corresponds to $q=0.1 \mathrm{~nm}^{-1}$.

Fig. 3. Circular integration of the differential SAXS patterns, $I_{\text {def, }}$ as a function of elapsed time, $t$.

Fig. 4 Stress relaxation behavior of IR3 at $0{ }^{\circ} \mathrm{C}$ (a) and at room temperature (b).

\section{GRAPHICAL TOC SUMMARY}

Small-angle X-ray scattering (SAXS) patterns of stretched vulcanizates of synthetic polyisoprene was recorded. The samples were quickly stretched to the prefixed strain and allowed to relax for $1 \mathrm{~h}$. Even below the critical strain, additional development of equatorial streaks was detected in the differential SAXS patterns. This result suggests the growth of the density fluctuation elongated in the stretching direction, which is not directly related to strain-induced crystallization. 
Fig. 1
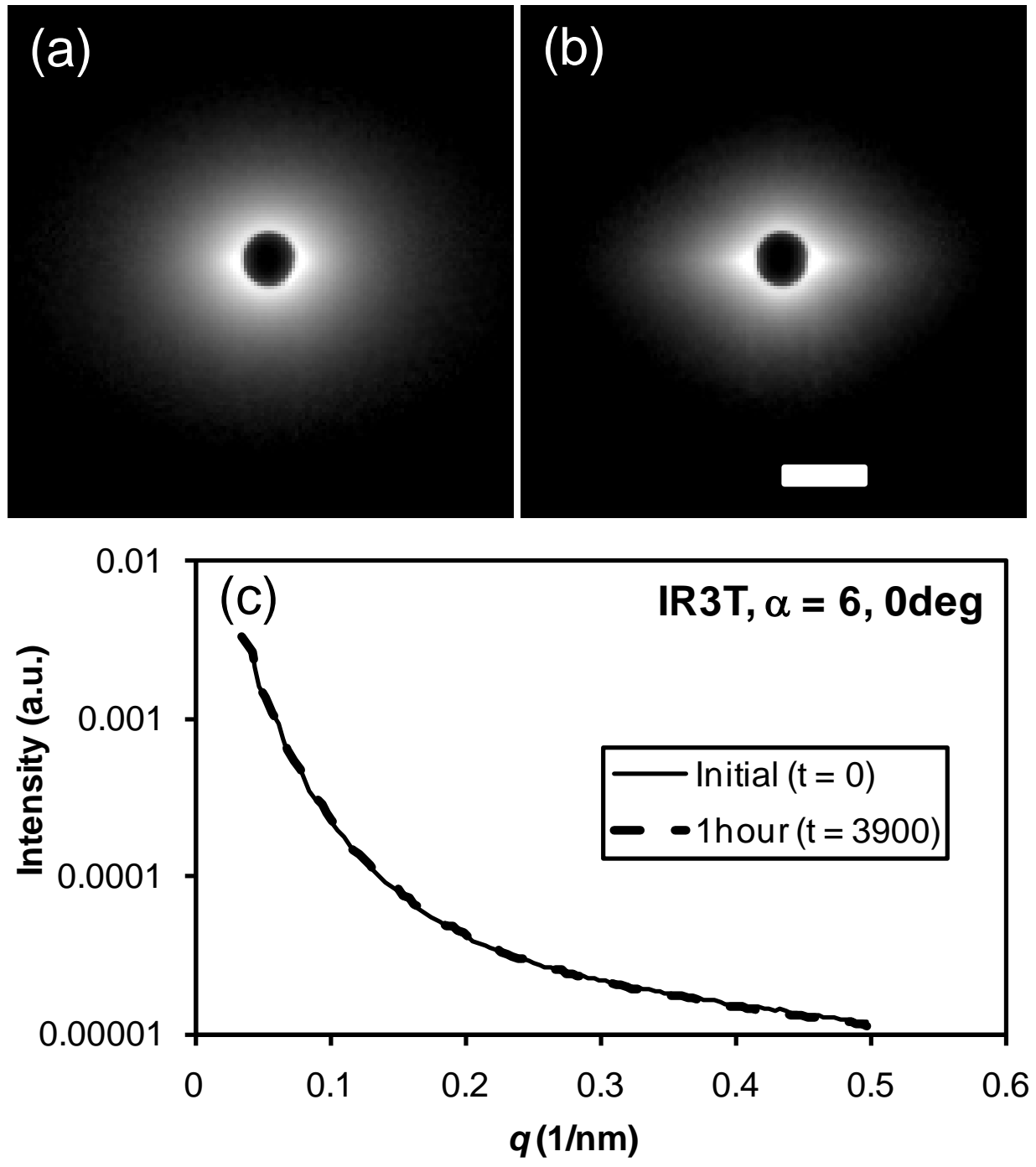


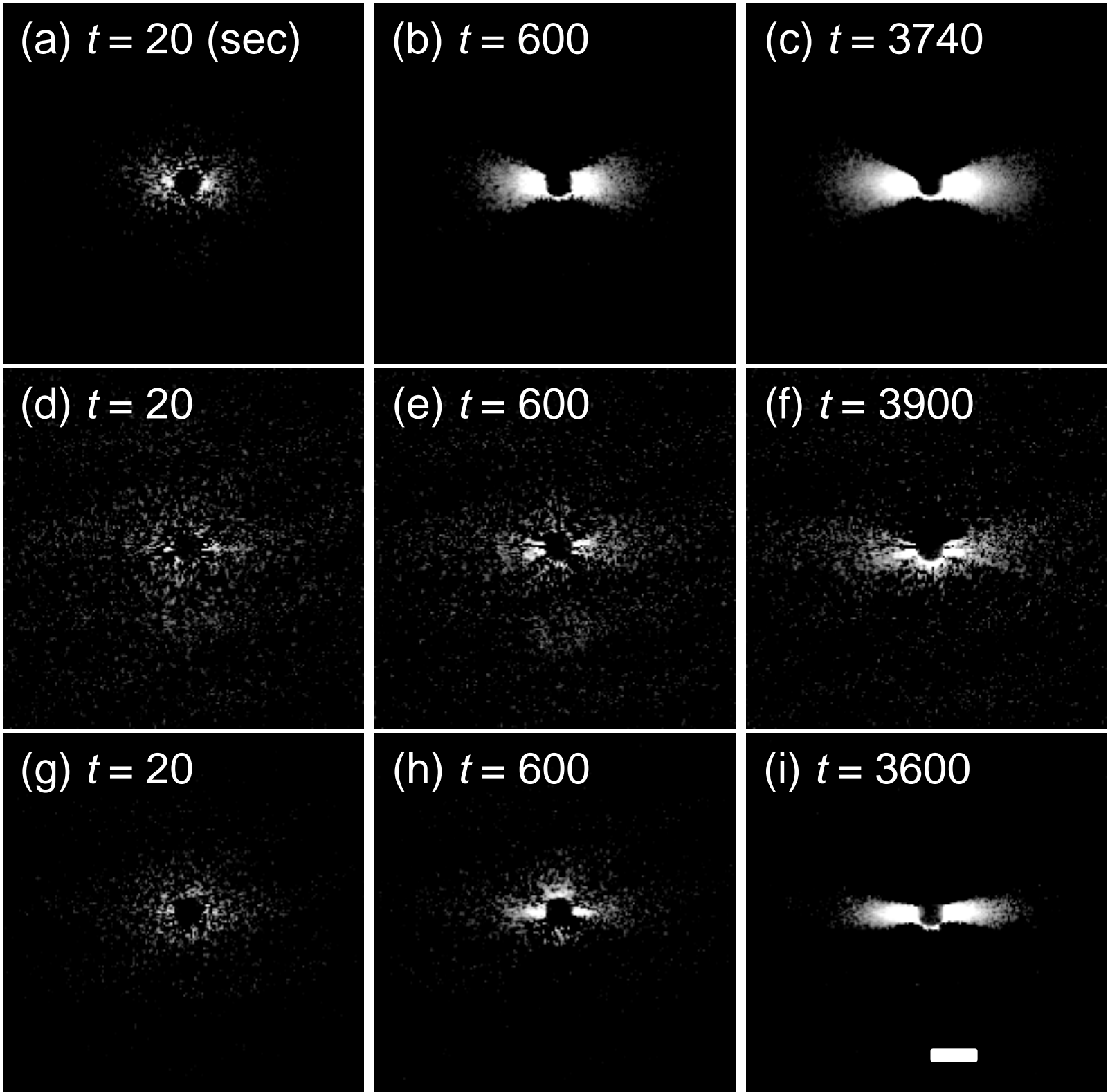


Fig. 3
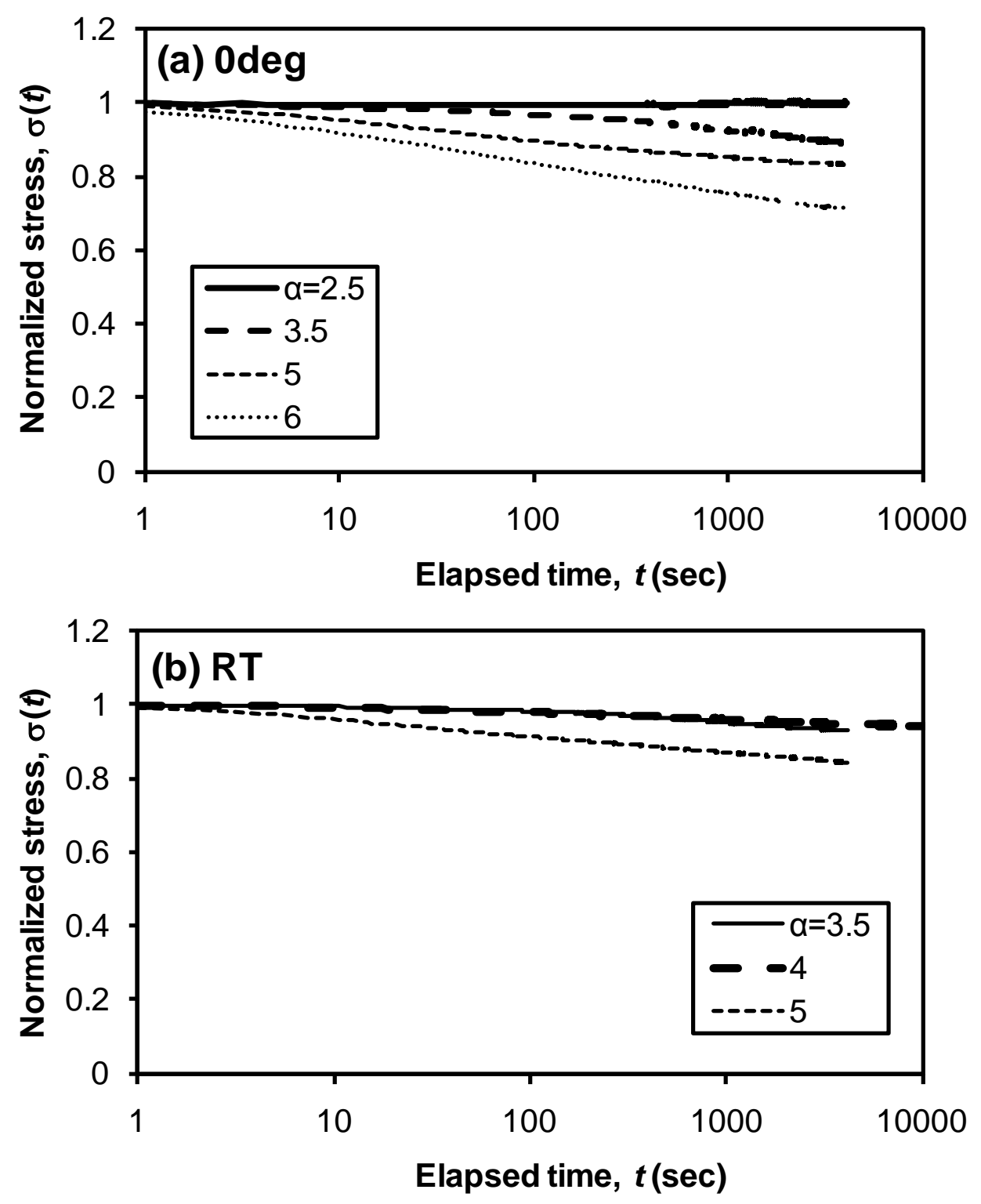
Fig. 4
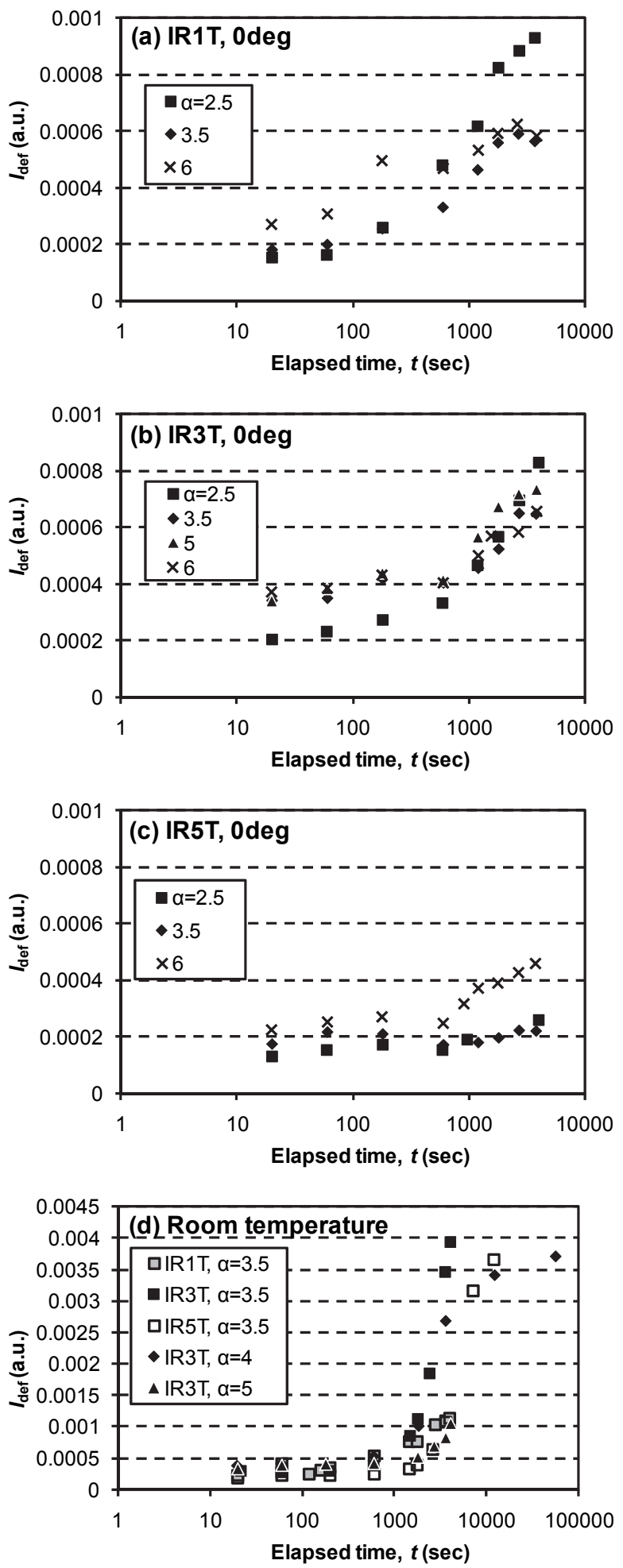
GRAPHICAL TOC

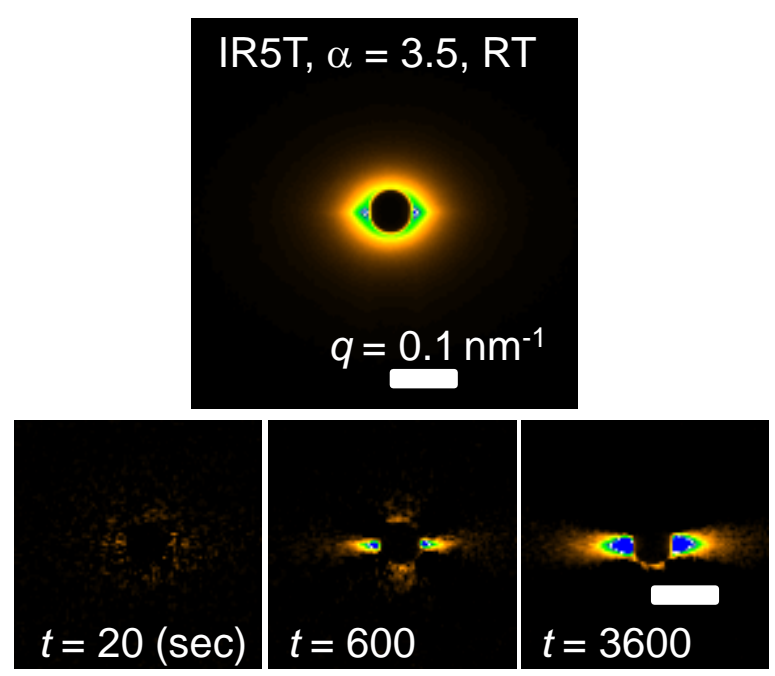

